\title{
Study on the Impact of Fintech and Debt Leverage on Systemic Financial Risk Transmission Mechanism
}

\author{
Chunyu Dong ${ }^{1,}$ "Shiyun $\mathrm{XiaO}^{2}$ Shouwei $\mathrm{Li}^{3}$
}

\author{
${ }^{1}$ School of Big Data Application and Economics, Guizhou University of Finance and Economics (Guiyang School of \\ Big Data Finance) Guiyang, Guizhou, China \\ ${ }^{2}$ School of Big Data Application and Economics, Guizhou University of Finance and Economics (Guiyang School of \\ Big Data Finance) Guiyang, Guizhou, China \\ ${ }^{3}$ School of Big Data Application and Economics, Guizhou University of Finance and Economics (Guiyang School of \\ Big Data Finance) Guiyang, Guizhou, China \\ *Email:729315409@qq.com
}

\begin{abstract}
This paper analyzes the contagion mechanism of systemic financial risk from the perspectives of fintech and debt leverage, and the analysis results show that the impact of fintech development on the occurrence of systemic financial risk is both exacerbated and mitigated. The mitigating effect is mainly in the reduction of information asymmetry and the upgrading of risk forecasting indicators; at the same time, excessive debt leverage can also lead to systemic risk due to the correlation between different sectors of the economy. The paper concludes with recommendations based on the findings.
\end{abstract}

Keywords: Financial technology, debt leverage, systemic financial risk.

\section{INTRODUCTION}

After the outbreak of the global financial crisis in 2008, China's economy was also affected to a certain extent. Over the years, the country has made many initiatives to stabilize the stable development of the domestic economy, but at the same time, new financial risks have been laid down. In recent years, the continuous innovation and development of financial technology, accompanied by a relatively relaxed economic environment in China, has made corporate financing easy and fast. On the one hand, this has led to a rapid shift in China's economic structure and high-quality development, but on the other hand, it has also increased the possibility of systemic risks. 2020, with the outbreak of the epidemic, many small and medium-sized enterprises were in deep water, and on March 6, 2020, the central bank implemented a downgrade, releasing 550 billion yuan of funds to alleviate the problem of difficult corporate financing, these initiatives promote economic vitality at the same time The possibility of systemic financial risk eruption was also exacerbated. 2020 the end of Ant Financial listed failed, and on April 10, 2021, the General Administration of Market Supervision ordered Alibaba Group to pay an antitrust fine of 18.228 billion yuan in accordance with the law. Ant Financial Services, as a domestic fintech giant, blatantly used its market monopoly

\section{LITERATURE REVIEW}

Systemic financial risks are non-diversifiable risks that cannot be eliminated through diversification and other means, and their contagion and diffusion paths are unpredictable and varied, so once such risks occur, they are unmatched by non-systemic risks in terms of both remedial measures and damage levels compared to non-systemic risks. Tao Ling [1] classifies the mechanisms that lead to the spread of systemic risks into three categories, namely credit crunch mechanism, liquidity crunch mechanism and asset price volatility, and she argues that these three mechanisms contribute to the outbreak of systemic crises in terms of liquidity risk, shadow banking risk, real estate market risk and debt risk, respectively, and Luo Hang [2] argues that with the progress of science and technology, the systemic crisis occurrence shows different trends along with the progress of information technology, on the one hand, information technology increases the transparency of financial transactions and weakens information asymmetry, which in turn helps to suppress the 
occurrence of systemic crises, on the other hand, the development difference between regulation and information technology makes the possibility of systemic risk increase. By studying the relationship between systemic risk and accommodative monetary policy and high leverage, Chen Guojin[3] concludes that accommodative monetary policy, macroprudential policy, and high leverage significantly increase the results of systemic risk-taking by banks.

Debt leverage refers to the debt financing of enterprises in their business activities, and for listed companies, there are two main channels of financing: debt financing and equity financing, and once an enterprise has a financial crisis, the risk will spread from the above two channels, and through the accounting linkage of the balance sheet, it will spread to other sectors, triggering systemic financial risk. Ma [4] argues that, compared with developed countries, although China's nominal leverage ratio is not high, the actual potential risk is not small, mainly because there is more hidden debt in China, while the growth rate of debt is also too fast, effectively resolving the high debt leverage ratio and preventing systemic financial risks,, is currently the top priority of China's financial supervision. From the perspective of debt rollover, Zhang Yilin[5] examines the mechanism of economic uncertainty on banks' debt rollover decisions and corporate leverage, arguing that banks' persistent increase in debt to insolvent enterprises to expand debt leverage will exacerbate economic uncertainty and will expand the potential for systemic financial crisis to occur.

Fintech refers to the convergent industry of finance and IT, which innovates the products and services provided by the traditional financial industry through various types of technology to improve efficiency and effectively reduce operating costs. Liao Min argues that there is a clear difference between the Internet economy proposed in China and FinTech, and that the Internet and mobile communication are only a tool and means for FinTech to serve the financial industry, and that FinTech's intrinsic core follows the laws of financial development. Fang Yi [6] illustrates the contagion mechanism between the development of fintech and systemic risk from three aspects: internet lending business, artificial intelligence and digital currency, and argues that systemic risk triggered by fintech is likely to erupt from these three aspects if there is no micro-prudential regulation and prevention mechanism.From the above literature, it can be seen that systemic financial risks are hidden in every link of economic activities, especially prominent in recent years in financial technology and debt leverage. On the one hand they favorably promote the conversion and upgrading of China's economic structure, but the resulting potential risks cannot be ignored, analyzing the transmission mechanism of systemic financial risks and the impact of both on them from two perspectives of financial technology and debt leverage, can The analysis of the transmission mechanism of systemic financial risks from the perspectives of both fintech and debt leverage and the impact of both on them can effectively recognize the process of systemic financial occurrence and transmission, and then formulate scientific and reasonable policy measures to prevent the occurrence of risks and ensure the healthy and stable development of China's economy and finance.

\section{STUDY ON FINTECH AND SYSTEMIC RISK TRANSMISSION MECHANISM}

With the continuous development of financial markets, systemic risks are hidden in various areas of financial markets. The emergence of financial technology has made financial business and transactions more abundant and extensive, and its contagion mechanism for systemic financial risks can be broadly divided into three aspects: first, Internet lending and artificial intelligence investment, second, the prevalence of digital currencies, and third, regulatory technology.

\subsection{Internet Lending And Artificial Intelligence Algorithms}

Internet lending, as the initial product of fintech, has created a frenzy in the financial sector, which also makes the risk spread among various sectors of fintech, and even more so, affects the traditional financial sector and market, forming a systemic financial risk, therefore, compared to the traditional financial sector, the fintech sector is more prone to form a systemic financial risk for two reasons, one is that the fintech sector in terms of funding is mainly linked to the real economy sector, such transactions have a long investment cycle, slow return of funds, and do not take advantage of liquidity, however, the liabilities of fintech often present a short-term debt situation, so there is a serious mismatch in funding, at the same time, the Internet big data and other information technology as a carrier of fintech, so that creditors, debtors and other customer objects and the fintech sector related to the intersection and penetration between And the development of fintech business is more extensive, with the trend of mixed business, thus more likely to generate systemic financial risks. When a P2P platform has a credit crisis or financial crisis, the rapid spread of information on the Internet will cause a large number of customers to panic and a run on the platform, and when the platform is unable to meet the redemption requirements of customers, this risk will infect other similar P2P platforms. This contagion channel can be called the expectation channel, i.e. the effect of market panic, which makes investors have negative expectations of other platforms due to the asymmetry of information. Another channel can be called the capital channel, that 
is, there are financial and business transactions between different fintech sectors, the collapse and bankruptcy of a platform will affect other related platforms, these two channels make the risk exposure level rise, the so-called "lightning" phenomenon, the crisis triggered by the platform is very likely to be in the fintech The crisis triggered by the platform is likely to be contagious among other sectors. At the same time, the risk in the field of financial technology will gradually spread to the traditional financial industry such as banks, stock market and other areas, such as some investors with the P2P platform financing for stock investment, increase leverage, once there is a break in funding, selling stocks and other phenomena caused by stock price fluctuations, will increase leverage or losses, the same banking sector due to the existence of funds trusteeship or guarantee cooperation with the platform, will also be impacted. This makes the systemic financial risk intensify and spread.

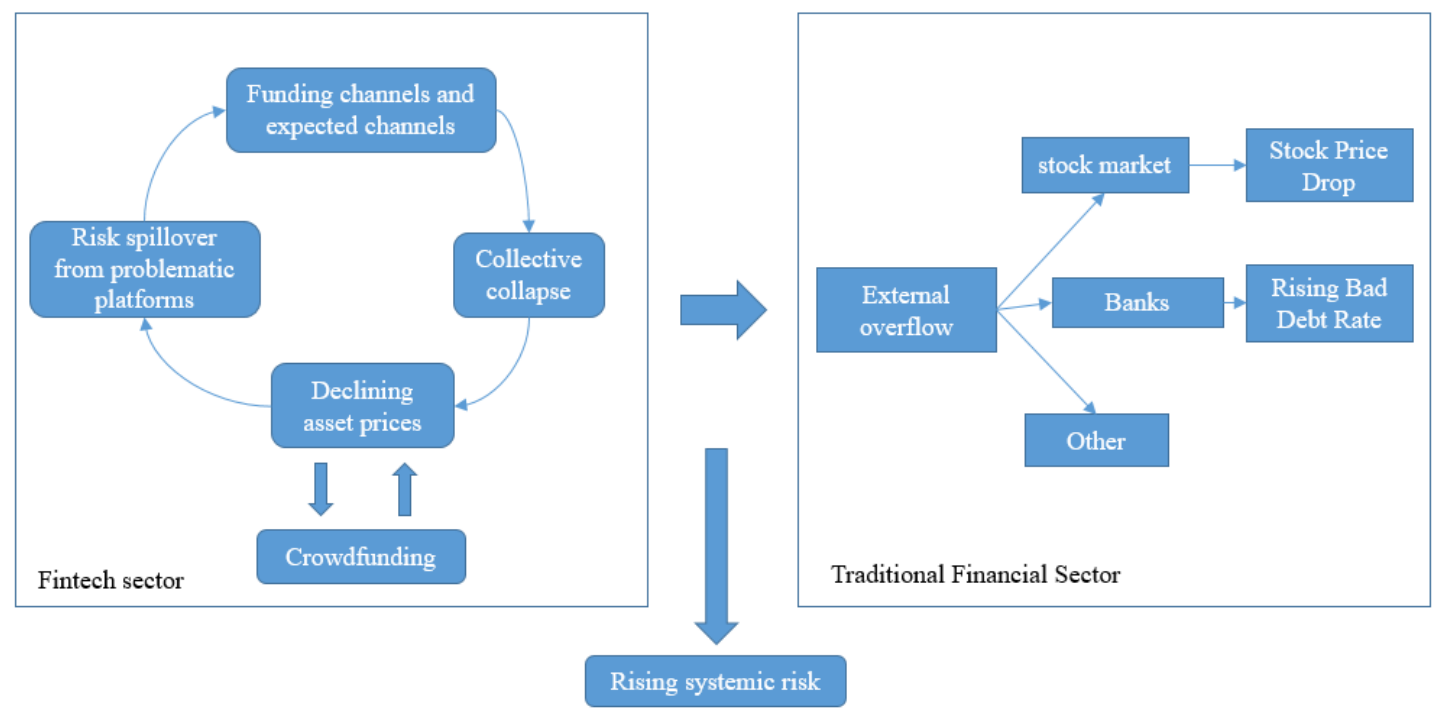

Figure 1 Internet lending risk contagion mechanism

Artificial intelligence algorithms are the latest product in the field of financial technology, which makes it easier and more efficient for financial institutions to operate their systems based on a large amount of data analysis and the use of big data technology to mitigate a large number of costs, however, when artificial intelligence technology is increasingly used in financial transactions, it leads to the homogeneity of the solutions chosen by artificial intelligence due to technical algorithms and data convergence, which makes market investors to engage in the same strategic investment and risk management behavior in the trading process, which in turn amplifies the inherent risk in the fintech sector. The more obvious characteristics include smart investment advisors, whose trading behavior tends to be the same when transactions with similar algorithms or similar programs are conducted between clients and financial institutions, and if the financial system is subject to other shocks at this time, so the smart investment advisors with convergent algorithms will propose corresponding selling strategies, and when the number of participants is large, it will cause market panic and lead to a decline in the prices of assets in the stock market and other capital markets, spreading the risk to these financial sectors, increasing the likelihood of systemic financial risk.

\subsection{Digital Currency}

As a carrier of new credit system, digital currency has two sides to the contagion mechanism and impact of systemic financial risk. On the one hand, the infrastructure possessed by fintech itself allows digital currencies to be combined with individual credit management platforms, and the credit construction and credit platform vigorously built by fintech can make the information asymmetry between the two sides of the transaction weaken, which to a certain extent mitigates the systemic financial risks caused by information asymmetry and credit crisis in the traditional financial industry, while digital currencies, such as the current blockchain At the same time, digital currencies such as the current blockchain, with its peer-to-peer distributed model, can also enhance transparency and security to a certain extent. 


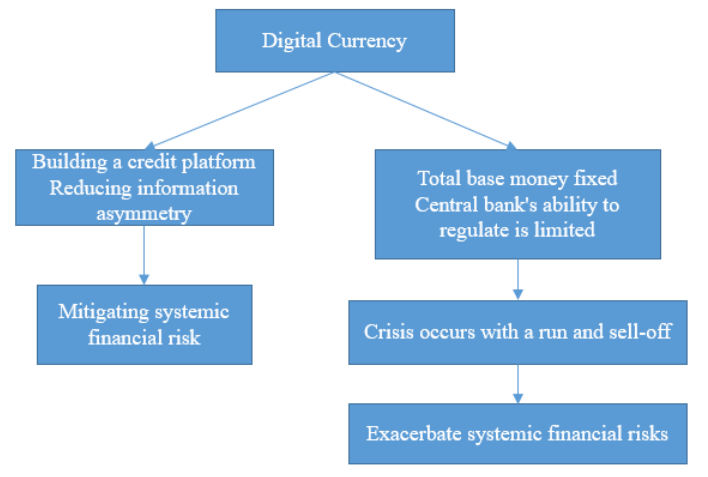

Figure 2 digital currency risk contagion mechanism

On the other hand, although there are still many irregularities in the development of digital currency and it is still a long way from the legal tender system, the number of digital currencies traded in the market is still huge and cannot be ignored. Under the current monetary system, the total amount of base currency is decided by the central banks, and financial institutions create more forms of currency for circulation based on the base currency, similarly, the base of digital currency Similarly, the base currency of digital currency will also generate higher forms of money through the leverage mechanism of the financial system, i.e., there is a multiplier effect, and the central bank is not able to actively regulate this form of leverage mechanism, so when there is a crisis in the financial market, panic will make the market appear violent fluctuations, triggering a systemic financial crisis.

\subsection{Regulatory Technology}

Fintech's regulatory technology also affects systemic financial risk to varying degrees in different ways. On the plus side, the development of FinTech and Internet technology complement each other, providing the financial industry with more new indicators for risk monitoring, as well as making operational vulnerabilities easier to detect and widening the channels for prediction and prevention. In addition, fintech has improved regulatory technology and thus enhanced the regulatory capacity of the financial industry, with a broader regulatory coverage that extends the regulatory field from real finance to Internet finance, enabling commercial banks, monetary authorities and other macroeconomic entities to enhance their risk prevention and early warning systems, as well as weakening information asymmetry among fintech participants, reducing credit volatility, and thus making asset price volatility, mitigating the risk of systemic financial crises.

However, information technology and financial technology are updated and upgraded rapidly, and financial regulation lags behind, while the development of financial technology is rapid, and financial regulation technology lags behind financial product innovation, which makes it easy to breed risks in gray areas. On the other hand, with its short review and assessment and balance cycle, the release of new products in the financial system is more likely to generate information asymmetry between regulation and products, increasing the moral hazard between government regulatory agencies and banking enterprises, and more quickly impact the financial system to cause the spread of systemic financial risks. As shown in Figure 3.
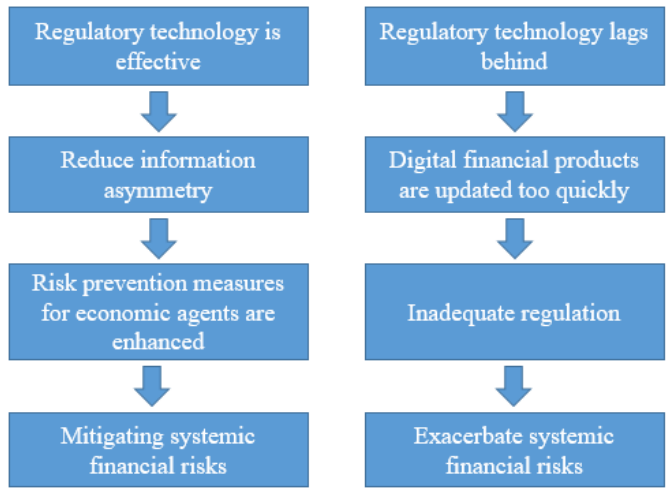

Figure 3 regulatory technology risk contagion mechanism

\section{STUDY ON DEBT LEVERAGE AND SYSTEMIC RISK CONTAGION MECHANISM}

Since the international financial crisis in 2008 , debt leverage in all sectors of the national economy has risen significantly, especially in the non-financial corporate sector and the financial sector. In recent years, China has been vigorously implementing the "leverage reduction" policy, and the macro leverage ratio was $270.1 \%$ in 2020 . Among them, the leverage ratio of the residential sector is $62.2 \%$. The leverage ratio of the non-financial corporate sector is $162.3 \%$. The leverage ratio of the government sector is $45.6 \%$. It is an extremely common phenomenon in economic activities for enterprises to borrow to operate, but excessive debt leverage not only brings the possibility of financial crises for the enterprises themselves, but also spreads such crises to other economic sectors in different forms, thus generating a contagion mechanism and aggravating the occurrence of systemic financial crises.

Generally speaking, the transmission mechanism of systemic risk from corporate debt leverage can be divided into two types of channels, one is through the debt financing channel and the other is through the equity financing channel. When the probability of corporate financial default rises, the risk of financial default rises accordingly and then propagates through both types of channels, mainly because the balance sheet is correlated, and the fall in the value of equity and risky debt of the shocked sector, holding The fall in the value of equity and risky debt in the shocked sector 
leads to a loss in the value of assets in other sectors that hold equity or debt-like assets in the shocked sector, and a chain reaction of equity and risky debt values leads to further transmission of losses to other sectors of the national economy. In the time dimension, as the debt leverage of a certain enterprise increases, when the crisis causes the volatility of financial markets to climb, the level of risk in all sectors of the national economy rises significantly, and the macro-financial risk in each sector will accelerate to accumulate and export to other nodes in the network structure, eventually causing systemic risk.

\section{CONCLUSION}

\subsection{Summary}

Financial activities in the field of fintech, such as Internet lending and artificial intelligence technology, while facilitating financial transactions and improving service efficiency, are subject to "lightning" and "herding effect", and once the market panics, the resulting fluctuations in market asset prices can easily trigger a systemic crisis. Once the market panic, the resulting volatility of market asset prices may easily trigger a systemic crisis. At the same time, the characteristics of digital currency is not restricted by the central bank also to a certain extent to prevent the crisis laid a hidden danger, the lag and gap of the regulatory mechanism makes the field of financial technology more vulnerable to attacks and transmission of risk.

The development of fintech also has a mitigating effect on the occurrence of systemic financial risks, mainly in terms of the transparency characteristics of fintech and the vigorous construction of credit platforms, which largely alleviate the phenomenon of information asymmetry between market traders. In addition a large number of new monitoring indicators make the risk prevention and warning function more prominent and make up for the regulatory gap or lag.

Due to the correlation of balance sheets among various sectors of the national economy, excessive debt leverage can make enterprises transfer risks to other sectors through both debt and equity channels in case of financial crises, thus increasing the possibility of crises.

\subsection{Suggestions}

organizations such as monetary issuing authorities, banking and financial institutions and government departments implement macro-regulation and reasonably build information technology into financial development strategies and development practices.

Participating entities in the field of financial technology should increase the construction of credit platforms and credit collection to reduce information asymmetry in the financial system. Regulators should make full use of information technology to play the role of financial innovation guidance and supervision of banking supervision.

Establish a sound macro-financial risk monitoring and early warning system with debt leverage as the key factor for investigation, further strengthen the monitoring, analysis and early warning of debt leverage levels and macro-financial risk indicators in all sectors of the national economy, and achieve early detection, prevention and disposal of risks. At the same time, we will accelerate the construction of multi-level capital market, vigorously develop equity financing, and achieve the deleveraging of non-financial enterprises in a smooth and orderly manner.

\section{ACKNOWLEDGMENTS}

This work is supported by National Natural Science Foundation of China (Grant No. 71663010), The Innovation Exploration and Academic New Seedling Project of Guizhou University of Finance and Economics "Research on Supply Chain Financial Credit Mechanism Driven by Blockchain Technology" (Guizhou Science and Technology platform talents [2017]No. 5736-018)

\section{REFERENCES}

[1] Tao L,Zhu Y. Monitoring and metrics of systemic financial risk--a study based on the Chinese financial system[J]. Financial Research,2016(06):18-36.

[2] Luo Hang, YanDawei,WangRui. Research on the impact mechanism of financial technology on systemic financial risk diffusion[J]. Southwest Finance,2020(06):87-96.

[3] Chen, G. J., Jiang, X. Y., and Zhao, Xiangqin. Monetary policy, macroprudential supervision and systemic risk-taking of banks[J]. Systems Engineering Theory and Practice,2020,40(06):1419-1438.

[4] Ma JT, Dong SJ, Shi HX, Xu J, Ma SF. China's leverage ratio and systemic financial risk prevention[J]. Finance and Trade Economics,2016,37(01):5-21.

[5] Zhang Yilin,Pu Ming. Debt rollover and structural deleveraging[J].EconomicResearch,2018,53(07):32 -46 .

[6] Fang Y, Wang Zelui, Wang Wei, Wang Yanru. Systemic risk in fintech: an endogenous risk perspective[J]. Journal of Central University of Finance and Economics, 2020(02):29-3 